\section{Cont $870965--4$}

To be submitted for inclusion in the conference proceedings of the International Conference on Chemistry and Migration Bohavior of Actinides and Fission Products in the Goosphoro, Munich, September 14-18, 1987

CONF-870965--4

DE88 003040

\title{
DETECTION AND SPECIATION OF TRANSURANUM EEMENTS IN SYNTHETIC GROUNDWATER VIA PULSED-LASER EXCITATION
}

\author{
J. V. Beitz, D. L. Bowers, M. M. Doxtader, V. A. Maroni, and D. T. Reed \\ Argonne National Laboratory \\ Argonne, IL 60439 \\ USA
}

\begin{abstract}
High sensitivity methods for detection and speciation of complexed transuranium ions in synthetic basalt groundwater, and simplified analogs. are being developed which exploit advances in pulsed laser technology. The first demonstration of high sensitivity detection of a transuranium ion at temperatures significantly above ambient is reported using laser photoacoustic spectroscopy (LPAS). The existence of enhanced LPAS signal amplitudes with increasing temperature in aqueous solution is confirmed in LPAS spectra recorded at $30 \mathrm{C}, 60 \mathrm{C}$ and $90 \mathrm{C}$ using micromolar concentrations of ${ }^{241} \mathrm{Am}^{3+}$. A detection sensitivity of 8.5 parts per trillion (weight basis) of ${ }^{244} \mathrm{~cm}^{3+}$ in a simplified basalt groundwater at $22 \mathrm{C}$ has been achieved using laser-induced fluorescence spectroscopy (LIF). This corresponds to $1 \times 10^{8} \mathrm{~cm}^{3+}$ ions in the laser beam. The detailed spectroscopic information obtained by this method points to the existence of previously unobserved $\mathrm{Cm}^{3+}$ species. A brief assessment of the applicability and sensitivity of LPAS and LIF methods for speciating transuranium ions in near-neutral $\mathrm{pH}$ aqueous solution, such as the groundwater expected in a basalt nuclear waste repository, is presented.
\end{abstract}

\section{DISCLAIMER}

This report was prepared as an account of work sponsored by an agency of the United States Government. Neither the United States Government nor any agency thereof, nor any of their employees, makes any warranty, express or implied, or assumes any legal liability or responsibility for the accuracy, completeness, or usefulness of any information, apparatus, product, or process disclosed, or represents that its use would not infringe privately owned rights. Reference herein to any specific commercial product, process, or service by trade name, trademark, manufacturer, or otherwise does not necessarily constitute or imply its endorsement, recommendation, or favoring by the United States Government or any agency thereof. The views and opinions of authors expressed herein do not necessarily state or reflect those of the United States Government or any agency thereor. 
Studies of transuranium ions in synthetic basalt groundwater, or simplified analogs thereof, have been carried out using the complementary techniques of pulsed laser photoacoustic spectroscopy (LPAS) and laser-induced fluorescence (LIF). These studies have been undertaken to support the Basalt V/aste Isolation Prc ject of the U.S. Department of Energy and to further fundamental understandirg of the chemical and physical behavior of transuranic ions in aqueous solution. The suitability of these techniques for the speciation of trace level complexed radionuclide ions in solutions typical of those expected in a basalt repository is being investigated. The expected groundwater is essentially a dilute (circa $0.01 \mathrm{M}$ ) $\mathrm{NaCl}$ solution with lesser, but potentially significant, amounts of carbonate, fluoride and sulfate as complexing anions as well as other cations such as $\mathrm{Ca}^{2+}$. The composition of a representative synthetic basalt groundwater, designated GR-4, has been reported by Doxtader et al [1] The solution conditions expected to be encountered in a basalt repository during the controlled release period include $\mathrm{pH}$ values from 6 to 10 (reducing conditions) and temperatures of $50 \mathrm{C}$ to in excess of $150 \mathrm{C}$.

This work builds on the LPAS studies carried out by Patel and Tam[2] who first demonstrated high LPAS sensitivity in aqueous solution using microsecond excitation[3] and on actinide LPAS studies carried out by Schrepp, Stumpe, Kim and co-workers[4,5,6,7] who demonstrated high LPAS sensitivity at ambient temperature using nanosecond excitation. A significant advance reported here is achievement of high LPAS sensitivity at $90 \mathrm{C}$ in carrying out speciation studies of $\mathrm{Am}^{3+}$ in a carbonate solution. While the majority of actinide species likely to occur in groundwater in a nuclear waste repository site are expected to be nearly non-luminescent and, therefore, por candidates for detection via LIF, LIF has the potential to be a more sensitive method than LPAS for detection and speciation of complexes of uranyl, $\mathrm{Cm}^{3+}$ and, possibly, $\mathrm{Am}^{3+}$. The work we report here shows that LIF is the better method for detection and speciation of $\mathrm{Cm}^{3+}$.

Speciation of actinide elements and their complexes in synthetic groundwater via LPAS or LIF relies on the characteristic $f-f$ absorption bands of actinide ions. Carnall[8] and Carnall and Crosswhite[9] have reviewed actinide ion spectroscopy and Newton and Sullivan[10] have reviewed the properties of actinide carbonato complexes including their spectra. The $f-f$ bands of actinides typically are narrow, but weak and, in most cases, are altered in position and shape on complexation. Pulsed LPAS relies on non-radiative decay of the initially excited electronic state land all lower lying electronic states coupled to it) to be fast compared to the acoustic transit time across the laser beam cross-section in the sample cell. In some cases, notably uranyl and $\mathrm{Cm}^{3+}$, non-radiative decay can be sufficiently slow that not all of the absorbed laser light is converted into thermal motion of the solvent in a time short compared to the acoustic transit time. In such cases, LIF detection provides extremely high detection sensitivity and so complements LPAS studies. 
Beitz and Hessler[11] have reviewed likely actinide detection limits using LIF. The general field of the identification of oxidation states of ultre-trace elements by radiation detection was recently reviewed by Guillaumont. Chevallier, and Adloff[12].

\section{Exporimental apparatus and mothods}

The LPAS apparatus used in this work has been described previously [1] Briefly, a pulsed dye laser (Lambda Physik FL3002 dye laser pumped by an EMG $201 \mathrm{MSC} 308 \mathrm{~nm}$ XeCl excimer laser) is used as an excitation source. Its beam impinges on a sample solution contained in a thermostated quartz sample cuvette. A piezoelectric transducer (PZT) in acoustic contact with the sample cell is used to measure the amplitude of the resulting acoustic wave. A $1 \mathrm{~cm}$ diameter by $61 \mathrm{~cm}$ long quartz rod provides both acoustic contact and thermal isolation between the sample cell and the PZZT. The output of the PZT, after preamplification and high and low pass filtering, is fed to a differential amplifier connected to a boxcar integrator. The gate of the boxcar is centered on one of the first maxima in the PZT response waveform and the boxcar is used to signal average the PZT response for a few laser pulses to several thousand laser pulses. The dye laser energy is simultaneously recorded using a second boxcar. The outputs of both boxcars are digitized and recorded on a computer. The PZT response is divided by the laser energy value to obtain a normalized PZT response. The reported LPAS spectra are the result of subtracting out the normalized response from a solution containing only $1.00 \mathrm{M} \mathrm{Na}_{2} \mathrm{CO}_{3}$ from the normalized PZT response from $\mathrm{Am}^{3+}$ in $1.00 \mathrm{M} \mathrm{Na}_{2} \mathrm{CO}_{3}$ solutions. The dye laser energy used (typically $3 \mathrm{~mJ} / \mathrm{pulse}$ ) was below that at which saturation of the normalized PZT response was observed in $\mathrm{Am}^{3+}$ solutions.

Sample solutions were prepared using analytical reagent grade inorganic chemicals and triply distilled water [13]. The ${ }^{241} \mathrm{Am}$ used in this work was radiochemically characterized so that it could be assayed using liquid scintillation counting. All carbonate containing solutions were stored in preconditioned polypropylene bottles. A stock solution of $1.00 \mathrm{M} \mathrm{Na}_{2} \mathrm{CO}_{3}$ was prepared and used for preparation of Am-containing solutions. An aliquot of a stock solution of 241 Am in nitric acid was taken to dryness by gentle heating and the required amount of sodium carbonate stock added to it to create a solution of $1 \times 10^{-3} \mathrm{M}$ (nominal) $\mathrm{Am}^{3+}$ concentration. This $\mathrm{Am}$ in $1.00 \mathrm{M} \mathrm{Na}_{2} \mathrm{CO}_{3}$ stock solution together with the $1.010 \mathrm{M} \mathrm{Na}_{2} \mathrm{CO}_{3}$ stock solution were used to prepare more dilute solutions.

The Am content of the resulting solutions were measured by liquid scintillation counting both before and after filtration through an 0.2 micron Microgon DynaGard syringe filter. Tests based on building histograms from observed LPAS response for each laser shot identified the Microgon DynaGard filter as superior to other syringe filters tested in minimizing interference from suspended particulate matter. The filtrate was used to fill high quality quartz fluorimeter cells $(1 \times 1 \mathrm{~cm}$ Hellma QS) equipped with quartz tubulation. The tubulation was sealed using a molded fluorocarbon fitting (Galtek SU8MN). This 
provided a seal which on non-radioactive test cells was found to be vacuum leak tight (leak rate less than $1 \times 10^{-9}$ std. $\mathrm{cm}^{3}$ of $\mathrm{He}$ per second). A dual temperature zone LPAS cell holder was used to keep the fubulation at a higher temperature than the lower section containing the liquid solution to eliminate condensation and any resultant change in solute concentration.

LIF studies of $\mathrm{Cm}^{3+}$ were carried out in a simplified basalt groundwater (SBGW) and in $0.10 \mathrm{M} \mathrm{HClO}_{4}$. The SBGW soluticn consisted of $0.01 \mathrm{M} \mathrm{NaCl}$ at $\mathrm{pH} 7.5$. The ${ }^{244} \mathrm{Cm}$ used had recently been separated from its decay daughter, $240 \mathrm{Pu}$, as was verified by alpha pulse height analysis. The $\mathrm{Cm}^{3+}$ in SBGW solution was prepared from a stock solution of ${ }^{244} \mathrm{Cm}$ in $0.1 \mathrm{M} \mathrm{HCl}$. An aliquot of the $\mathrm{Cm}$ stock solution was taken to dryness in a borosilicate glass vial using gentle heating and a stream of dry nitrogen gas. An aliquot of water was added and the solution was taken to dryness a second time. An aliquot of $0.01 \mathrm{M} \mathrm{NaCl}$ was added and the vial was gently agitated to bring the $\mathrm{Cm}$ into solution. Nitrogen gas was bubbled through the solution to reniove any remaining $\mathrm{CO}_{2}$. The $\mathrm{pH}$ of the purged solution was measured (Beckman model PHI 71 pH meter equipped with a Ross combination electrode) and found to be $7.48+/-0.02$. The purged solution was immediately transferred into a nitrogen gas purged fluorescence sample cell (Hellma OS $1 \times 1 \mathrm{~cm}$ fluorimeter cell equipped with a Corning Rotoflow fluorocarbon plug high vacuum stopcock). The $\mathrm{Cm}$ content of this solution was found to be $325+1-33$ parts per trillion (ppt) on a weight basis. We report the $\mathrm{Cm}$ content of this solution on a weight basis due to uncertainty as to $\mathrm{Cm}^{3+}$ species (mononuclear or polynuclear) actually present in it The $1.63 \times 10^{-9} \mathrm{M}$ (398 ppt) $\mathrm{Cm}^{3+}$ in $0.10 \mathrm{M} \mathrm{HClO}_{4}$ solution was prepared by adding an aliquot of the $\mathrm{Crn}$ stock solution to a borosilicate glass vial. An aliquot of $0.10 \mathrm{M} \mathrm{HClO}_{4}$ was added and the vial was gently agitated. The solution was then transferred into a clean fluorescence sample cell.

The apparatus used for fluorescence excitation is similar to one used previously for LIF studies of aquo $\mathrm{An}^{3+}$ ions[14,15] Currently, $f / 1$ light collection is used and the fluorescence light is analyzed using a circular variable interference filter (CVF) driven by a stepper motor. The CVF, an OCLI model VC180-017, provides circa $2 \%$ wavelength resolution. Fluorescence light is detected using an uncooled photomultiplier with a gallium arsenide photocathode (RCA 31034). A series of low fluorescence optical filters (Schot KV series) together with a potassium chromate solution filter minimized the effect of Rayleigh and Raman scattered laser light The amplitude of the initial spike due to the remaining scattered light was reduced using diode clipping. A transient digitizer (LeCroy TR8818) under the control of a DEC $11 / 23+$ minicomputer was used to measure fluorescence lifetimes. Fluorescence excitation and emission spectra were recorded using a gatsd boxcar integrator and a second boxcar was used to monitor dye laser energy. The boxcar outputs were digitized and stored on a computer. The fluorescence excitation spectra shown are the result of dividing the phototube signal by the laser power. Each point in the excitation spectra was divided by the corresponding laser wavelength to correct for having monitored laser energy (joules of light) instead of the number of incident photons. The sample temperature was $22+1-1$ 
Laser photoacoustic spectroscopy studies of $\mathrm{Am}^{3+}$ in carbonate solution

Primary emphasis in our LPAS studies has been on establishing the sensitivity of the technique for speciating actinides at temperatures significantly above ambient This work has emphasized studies of $\mathrm{Am}^{3+}$ since it has a favorable absorption band[16] near the minirnum absorbance wavelength of water. $\mathrm{Am}^{3+}$ also has a $\mathrm{J}=0$ ground state and its next higher lying state is a $\mathrm{J}-1$ state at about $2200 \mathrm{~cm}^{-1}[17]$. Due to the comparatively simple energy level structure of $\mathrm{Am}^{3+}$, little change is expected in the f-f absorption spectra of its complexes with ternperature although the relative amounts of each complex will, in general, be a function of temperature.

Studies were carried out primarily in $1.00 \mathrm{M} \mathrm{Na}_{2} \mathrm{CO}_{3}$ to minimize changes in Am speciation with temperature and to enable a wide range of Am concentrations to be studied. Figure 1 shows a comparison of LPAS absorption spectra recorded using $2.5 \times 10^{-6} \mathrm{M} \mathrm{Am}^{3+}$ in $1.00 \mathrm{M} \mathrm{Na}_{2} \mathrm{CO}_{3}$ at sample temperatures of $30 \mathrm{C}, 60 \mathrm{C}$, and $90 \mathrm{C}$. As expected, there is little change in the band shape. There is, however, a distinct overall increase in PZT response per unit incident laser energy. An enhancement of LPAS signal size per unit incident laser energy with increasing temperature in aqueous solution is expected from the LPAS theory of Nelson and Patel[18]. Their theory predicts the following relationship:

$$
v_{a}=k \times \frac{B v E a}{C_{p}}
$$

where $V_{a}$ is the output voltage of the acoustic transducer, $K$ is a constant for a given apparatus, $B$ is the isobaric compressibility of water. $v$ is the velocity of sound in water, $E$ is the laser pulse energy, $a$ is the absorption coefficient of the solution at the laser wavelength, and $C_{p}$ is the isobaric heat capacity per gram of solution. The above equation is expected to hold for a laser bearn diameter of a few millimeters, a transducer response time comparable to the acoustic transit time, and a weakly absorbing sample solution. All of these conditions are met in our experiments. Using literature values for $B[19] v[20]$ and $C_{p}[21]$ in Eqn 1, results in the expectation that at consiant Ea (i.e. per unit absorbed laser energy), the LPAS enhancement relative to $30 \mathrm{C}$ will be 1.77 at $60 \mathrm{C}$ and 2.34 at $90 \mathrm{C}$. The observed enhancement of the $507.6 \mathrm{~nm}$ peak of $\mathrm{Am}^{3+}$ in $1.00 \mathrm{M} \mathrm{Na}_{2} \mathrm{CO}_{3}$ shown in Figure 1. relative to $30 \mathrm{C}$, is 1.21 at $60 \mathrm{C}$ and 1.46 at $90 \mathrm{C}$. The observed enhancement of the $507.6 \mathrm{~nm}$ band of $\mathrm{Am}^{3+}$, based on band areas relative to the $30 \mathrm{C}$ spectrum, is 1.29 at $60 \mathrm{C}$ and 1.66 at $90 \mathrm{C}$. Comparing enhancements based on peak height versus peak area confirms there is only a small change in band shape.

The precise reason for the difference between the observed enhancements relative to those expected from theory is not understood at present in similar temperature dependent LPAS studies of $\mathrm{Ho}^{3+}$ in $\mathrm{HClO}_{4}$ in the 470 to 490 
$\mathrm{nm}$ region, we observed different enhancements for different $\mathrm{Ho}^{3+}$ absorption bands even though no significant changes in peak height were observed when the absorption spectrum of a similar $\mathrm{Ho}^{3+}$ solution was recorded as a function of temperature over the same range using a Cary $17 \mathrm{H}$ spectrometer. This suggests that the photophysics (energy transfer and relaxation rates) of the absorber may be a contributing factor. It should be noted, however, that the only previous test of aqueous solution LPAS enhancement with temperature, which is implicit in Nelson and Patel's theory[18], is Tam and Patel's study[3] of the optical absorbance of water. Tam and Patel measured the influence of temperature on the observed LPAS signal at $16,400 \mathrm{~cm}^{-1}$ and found fairly good agreement with Eqn 1. This is somewhat surprising since their transducer was evidently in good thermal contact with their sample and they do not report correcting for the influence of temperature on their transducer.

The concentration of $\mathrm{Am}^{3+}$ in $1.00 \mathrm{M} \mathrm{Na}_{2} \mathrm{CO}_{3}$ was varied to establish the LPAS detection sensitivity of our apparatus at $90 \mathrm{C}$. The LPAS spectrum of $1.2 \times 10^{-7} \mathrm{M} \mathrm{Am}^{3+}$ in $1.00 \mathrm{M} \mathrm{Na}_{2} \mathrm{CO}_{3}$ in the $495 \mathrm{~nm}$ to $525 \mathrm{~nm}$ region was measured at $90 \mathrm{C}$ using $3 \mathrm{~mJ}$ per laser pulse and averaging 300 laser pulses. Dividing the observed PZT signal per unit incident energy at the $\mathrm{Am}^{3+}$ absorption peak at $507.6 \mathrm{~nm}$ by the standard deviation of the baseline noise at $496 \mathrm{~nm}$ results in a calculated detection limit ( $/ \mathrm{N}-1)$ of $6 \times 10^{-9} \mathrm{M} \mathrm{Am}^{3+}$. Using Hobart et al's value[16] for the molar absorbance of $\mathrm{Am}^{3+}$ in carbonate media, this corresponds to a detection limit of $1.4 \times 10^{-6}$ absorbance units per $\mathrm{cm}$ of optical pathlength through the sample at $90 \mathrm{C}$.

LPAS studies of $\mathrm{Am}^{3+}$ above ambient temperature are continuing to be pursued using solutions which more nearly approximate the groundwater conditions near a nuclear waste repository sited in basalt rock (i.e. lower carbonate concentrations and in SBGW).

\section{Laser-induced fluorescence studies of $\mathrm{Cm}^{3+}$ in simplified basalt groundwater}

Laser-induced fluorescence is a powerful method of detecting luminescent species and, as such, complements LPAS which, in general, will underestimate the concentration of luminescent species. LIF studies of the transuranium elements Am[22l Cm[11], BK[14]. and Es[15] in solution as aquo 3+ ions have been reported. Of these species, the highest LIF sensitivity is expected for $\mathrm{Cm}^{3+}$. Yusov and co-workers have reported a $\mathrm{Cm}^{3+}$ detection limit of $10^{-10} \mathrm{M}$ for $\mathrm{Cm}^{3+}$ extracted into an organic phase which enhances $\mathrm{Cm}^{3+}$ fluorescence[23]. Beitz and Hessler[11] estimated that as littie as $3 \times 10^{-13} \mathrm{M}$ of $\mathrm{Cm}^{3+}$ should be retectable in aqueous solution via LIF using the $A$ to $Z$ transition of $\mathrm{Cm}^{3+}$ and time-correlated single photon counting. Using $10 \mathrm{~mW}$ average laser power and a less sensitive analog detection method, we now have measured a detection limit $(\mathrm{S} / \mathrm{N}=1)$ of $1.8 \times 10^{-11} \mathrm{M}$ for $\mathrm{Cm}^{3+}$ in $0.10 \mathrm{M} \mathrm{HClO}_{4}$ and 8.5 parts per trillion (weight basis) for $\mathrm{Cm}^{3+}$ in SBGW.

The fluorescence excitation spectra of $\mathrm{Cm}^{3+}$ shown in. Figure 2 were acquired using a maximum dye laser energy of $0.75 \mathrm{~mJ}$ per pulse. The effective 
wavelength resolution is $0.116 \mathrm{~nm}$ and there were 170 laser pulses per resolution element for comparison purposes, the two excitation spectra were scaled such that their peak heights were equal and their baselines at $403 \mathrm{~nm}$ were equal. It is evident that $\mathrm{Cm}^{3+}$ in SBGW absorbs in a band which is shifted to longer wavelength and is broader than that of aquo $\mathrm{Cm}^{3+}$. The molar absorbance at the peak of the $F$ band of aquo $\mathrm{Cm}^{3+}$ is $55.2 \mathrm{M}^{-1} \mathrm{~cm}^{-1}$ [24] There are no previous reports of the absorption spectrum of $\mathrm{Cm}^{3+}$ in nearneutral $\mathrm{pH}$ aqueous solution. The excitation spectrum of $\mathrm{Cm}^{3+}$ in SBGW shown in Figure 2 provides evidence that most of the $\mathrm{Cm}^{3+}$ is no longer present as the aquo ion. The nearest equivalent $\mathrm{An}^{3+}$ ion for which a body of solubility data exists is $\mathrm{Am}^{3+}$. Our finding that $\mathrm{Cm}^{3+}$ in $0.01 \mathrm{M} \mathrm{NaCl}$ at $\mathrm{pH} 7.5$ is not predominantly present as aquo $\mathrm{Cm}^{3+}$ is consistent with the distribution of $\mathrm{Am}^{3+}$ hydrolysis products at $\mathrm{pH} 7.5$ reported by $\mathrm{Kim}$ et ali[25] in which $\mathrm{Am}(\mathrm{OH})^{2+}$ is the predominant species. It is at variance with concentrations of Am solution species calculated by Silval26] for carbonate-free solution at pH 7.5 (ionic strength $0.1 \mathrm{M}$ ) in which aquo $\mathrm{Am}^{3+}$ is given as the predominant species. It is likely that $\mathrm{Cm}^{3+}$ in SBGW is primarily present as hydroxo species such as $\mathrm{Cm}(\mathrm{OH})^{2+}$ or $\mathrm{Cm}(\mathrm{OH})_{2}{ }^{1+}$.

Measurements of the fluorescence decay rate of the $\mathrm{A}$ state of $\mathrm{Cm}^{3+}$ were carried out via excitation of its $F$ state[24] Laser excitation at $397.7 \mathrm{~nm}$ allows most 1 st and $2 \mathrm{~d}$ Stokes spontaneous Raman scattered laser light to be removed by the optical filters used. The fluorescence wavelength range monitored was $591 \mathrm{~nm}$ to $603 \mathrm{~nm}$ (FWHM). Add-to-memory signal averaging of the output of the transient recorder was carried out for $20481 \mathrm{~mJ}$ laser pulses with a dwell time of 320 ns per transient recorder channel. The data for the two $\mathrm{Cm}$ solutions have been scaled for comparison purposes so that the initial fluorescence intensities were equal to 100. The upper solid line trace is the observed data for $\mathrm{Cm}^{3+}$ in SBGW and the lower solid line trace is the observed data for aquo $\mathrm{Cm}^{3+}$ in $0.10 \mathrm{M} \mathrm{HClO}_{4}$. The dashed line through each of the solid line traces is the result of fitting a single sxponential decay model to the observed data. The observed fluorescence lifetime of aquo $\mathrm{Cm}^{3+}$ in $0.10 \mathrm{M} \mathrm{HClO}_{4}$ is $68+1-3$ microseconds in good agreement with the earlier value of $65+1-2$ microseconds reported by Beitz and Hessler[11]

Fitting the fluorescence decay of $\mathrm{Cm}^{3+}$ in SBGW (Figure 3) to a single exponential decay model results in a calculated lifetime of $84+1-3$ microseconds, but a residuals plot shows that the observed data deviate systematically frorn a single exponential decay. Better residuals agreement is found carrying out a non-linear least fit to a double exponential decay model. The best fit is obtained for 0.32 of the fluorescence intensity arising from a species with a $16.4+/-6.6$ microsecond lifetime and 0.68 of the fluorescence decay arising from a species with a fluorescence lifetime of $92+1-2.6$ microsecond. This provides evidence that there is more than one $\mathrm{Cm}^{3+}$ species in the SBGW solution. Additional studies, including systematic variation of $\mathrm{COH}^{-} \mathrm{l}$, will be required to identify the actual $\mathrm{Cm}^{3+}$ species present

The fluorescence emission: spectrum (not shown) of each of the two $\mathrm{Cm}^{3+}$ solutions was recorded in the $560 \mathrm{~nm}$ to $640 \mathrm{~nm}$ region $\left(\mathrm{Cm}^{3+}\right.$ A state emission) 
at low resolution using the CVF system because of the comparatively low fluorescence light levels. The only difference in the emission spectra was that the band from aquo $\mathrm{Cm}^{3+}$ in $0.10 \mathrm{M} \mathrm{HClO}_{4}$ peaked at $593 \mathrm{~nm}$ and that from $\mathrm{Cm}^{3+}$ in SBGW peaked at $596 \mathrm{~nm}$. The observed FWHM of the $\mathrm{Cm}^{3+}$ emission peak in both cases was $15 \mathrm{~nm}$ which is only a little larger than the measured $12 \mathrm{~nm}$ FWHM resolution of the circular variable filter. This indicates that the true width of the $\mathrm{Cm}^{3+}$ emission band in either solution is less than $12 \mathrm{~nm}$ in good agreement with Beitz and Hessler's earlier report[11] that aquo $\mathrm{Cm}^{3+} A$ state omission resulting from $G$ state excitation peaked at $593 \mathrm{~nm}$ in a $8 \mathrm{~nm}$ FWHM band. There are no previous reports of the emission spectrum of $\mathrm{Cm}^{3+}$ in near-neutral $\mathrm{pH}$ aqueous solution against which to compare our observations.

The $\mathrm{Cm}^{3+}$ detection limit (S/N -1$)$ of our present LIF apparatus using 20481 $\mathrm{mJ}$ laser pulses is obtained from the fluorescence decay data shown in Figure 3. The signal-to-noise ratio for that data was calculated by integrating the fluorescence signal during its decay to 0.5 of its initial value and dividing by the RMS baseline noise integrated over the same number of microseconds. Dividing the $\mathrm{Cm}^{3+}$ concentration used for the fluorescence decay measurement by this observed signal-to-noise ratio gives the concentration of $\mathrm{Cm}^{3+}$ at which $\mathrm{S} / \mathrm{N}=1$. The resulting detection limits are $1.8 \times 10^{-11} \mathrm{M}$ for aquo $\mathrm{Cm}^{3+}$ and $8.5 \mathrm{ppt}$ for $\mathrm{Cm}^{3+}$ in SBGW. Taking the cross-sectional area of the laser beam into account, this corresponds to a detection limit of $1 \times 10^{8} \mathrm{~cm}^{3+}$ ions in the laser beam for the $\mathrm{Cm}^{3+}$ in SBGW solution.

\section{Assessment of the applicability of LPAS and LIF techniques to speciation of trace levels of complexed transuranic ions in basalt groundwater}

By combining LPAS and LIF techniques, the best possible sensitivities can be obtained in speciating actinides in synthetic basalt groundwater such as GR-4. It is of significance that LPAS signal amplitude has been shown to increase with increasing sample temperature since temperatures from $50 \mathrm{C}$ to in excess of $150 \mathrm{C}$ are expected in basalt repositories. Much experimental work remains to be carried out, however, before a full library of reference optical absorbance spectra is available to facilitate accurate and complete speciation of transuranic ions in groundwater.

Accurate assessment of likely LPAS detection limits is hampered by the lack of any reference spectra for most of the actinide complexes which potentially may occur in basalt groundwater. Only at high carbonate concentration is there an appreciable body of spectral information (see work cited by Newton and Sullivan[10]. There are, in general, several possible mononuclear complexes (i.e. metal-anion ratios of 1:1, 1:2, 1:3, etc) for actinides in solution with carbonate, fluoride, hydroxide and sulfate ions. Since basalt groundwater is a mixture of these complexing anions, there may also be at least some mixed anion complexes such as $\mathrm{Am}(\mathrm{OH}) \mathrm{F}^{1+}$ or $\mathrm{Pu}(\mathrm{OH}) \mathrm{CO}_{3}{ }^{1+}$. Particularly in the case of 4+ metal ions, there is considerable potential for polymer formation if an appreciable local concentration of the metal ion occurs during 
dissolution of the waste form. Almost nothing is known about such polynuclear metal complexes when they contain only a few metal ions per complex. Based on an LPAS sensitivity of $1.4 \times 10^{-6}$ absorbance units per $\mathrm{cm}$ using 300 laser pulses, each of $3 \mathrm{~mJ}$ energy, we expect the following detection limits (S/N-1): $6 \times 10^{-9} \mathrm{M} \mathrm{Am}^{3+}, 1 \times 10^{-8} \mathrm{M} \mathrm{Pu}^{4+}, 4 \times 10^{-8} \mathrm{M} \mathrm{PuO}_{2}{ }^{1+}$ and $2 \times 10^{-8} \mathrm{M} \mathrm{PuO}_{2}{ }^{2+}$ for the actinide as the carbonato species present in reported spectra[27,16] taken at high carbonate concentration. If, as we anticipate, full dye laser energy can be used without saturating the normalized LPAS response from $\mathrm{Pu}$ oxidation states, then detection limits of $3 \times 10^{-10} \mathrm{M} \mathrm{Pu}^{4+}, 1.2 \times 10^{-9} \mathrm{M}$ $\mathrm{PuO}_{2}{ }^{1+}$ and $6 \times 10^{-10} \mathrm{M} \mathrm{PuO}_{2}{ }^{2+}$ will bo reached using 2048 laser pulses. Determination of the transuranic species actually present in a groundwater solution, i.e. speciation, will require at least 10 to 20 times higher metal ion concentrations.

The work we report here has demonstrated an LIF detection limit of $8.5 \mathrm{ppt}$ for $\mathrm{Cm}^{3+}$ in a simplified basalt groundwater using our present apparatus. Using a picosecond excitation source, a cooled, gated, photomultiplier and

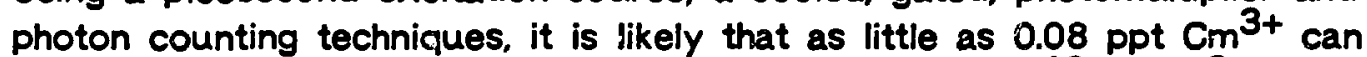
be detected using LIF. Detection of as little as $1 \times 10^{-10} \mathrm{M} \mathrm{Am}^{3+}$ should also be possible under such conditions in synthetic groundwater solutions at ambient temperatures. Once again, metal ion concentrations at least 10 to 20 times above the detection limit will be needed to carry out speciation. Little is known about the temperature dependence of the non-radiative decay rates of the fluorescing states of $\mathrm{Am}^{3+}$ or $\mathrm{Cm}^{3+}$, but some loss in detection sensitivity is likely to occur at elevated temperatures. Given what is known about the energy level structure of Pu oxidation states[8,9] LIF probably will not prove to be a high sensitivity detection method for $\mathrm{Pu}$

\section{Conclusions}

High LPAS sensitivity for transuranic ion speciation in solution has been demonstrated for the first time at temperatures significantly above ambient Our studies of $\mathrm{Am}^{3+}$ at micromolar concentrations in $1.00 \mathrm{M} \mathrm{Na}_{2} \mathrm{CO}_{3}$ at 30,60 and $90 \mathrm{C}$ have demonstrated the existence of enhanced LPAS signal amplitudes with increasing temperature. LPAS is the technique of choice for speciating 4+, 5+ and $6+$ oxidation states of transuranic elements with detection limits for $\mathrm{Pu}$ oxidation states in the $10^{-9} \mathrm{M}$ to $10^{-10} \mathrm{M}$ range likely to be achieved.

Laser-induced fluorescence has been shown to be a necessary complement to LPAS studies of transuranic ion speciation in solution. A detection limit of $8.5 \mathrm{ppt}$ for $\mathrm{Cm}^{3+}$ at ambient temperature in a simplified groundwater has been established using laser-induced fluorescence and spectral evidence obtained that previously unobserved $\mathrm{Cm}^{3+}$ species are present in this solution. The detection sensitivity of this technique is expected to make detailed speciation studies of $\mathrm{Cm}^{3+}$ feasible under all solution conditions expected to be encountered in a basalt nuclear waste repository. Application of state-of-the-art picosecond laser excitation may result in LIF detection limits for $\mathrm{Am}^{3+}$ which are superior to those attainable with LPAS. 


\section{Acknowledgements}

We thank J. C. Sullivan for assistance in preparing the curium solutions. This work was performed under the auspices of the Office of Basic Energy Sciences, Division of Chemical Sciences, U. S. Department of Energy, under contract number W-31-109-ENG-38 and the Basalt Waste Isolation Project, Office of Geologic Repositories, U. S. Department of Energy, under contract number DE-ACO6-77RL01030.

\section{References}

1. DOXTADER, M. M., MARONI, V. A., BEITZ, J. V., and HEAVAN, M: Laser photoacoustic spectroscopy for trace level detection of actinides in groundwater. In: Scientific Basis for Nuclear Waste Management X (J. K. BATES and W. B. SEEFELDT, eds.) Materials Research Society Symposium Proceedings vol 84, Materials Research Society, Pittsburg. 1987. pg 173.

2. PATEL, C. K. N and TAM A C: Pulsed optoacoustic spectroscopy of condensed matter. Rev. Mod. Physics, 53, 517 (1981).

3. TAM, A C. and PATEL, C. K. N: Optical absorption of light and heavy water by laser optoacoustic spectroscopy. Appl. Opt 18, 3348 (1979).

4. SCHREPP, W., STUMPE, R, KIM, J. I., and WALTHER, H: Oxidationstate-specific detection of uranium in aqueous solution by photoacoustic spectroscopy. Appl. Phys. B 32, 207 (1983).

5. STUMPE, R, KIM, J. I., SCHREPP, W., and WALTHER, H: Speciation of actinide ions in aqueous solution by laser-induced pulsed photoacoustic spectroscopy. Appl. Phys. B 34, 203 (1984).

6. EISWORTH, M., KIM, J. I., and LIERSE, CH: Optical absorption spectra of Pu(IV) in carbonate/bicarbonate media Radiochim. Acta 38, 197 (1985).

7. STUMPE, R and KIM, J. I: Laser-Induzierte Photoakustiche Spectroskopie Zum Nachweiss Des Chemischen Verhaltnes von Aktiniden. RCM 02386, dated June 1986.

8. CARNALL, W. T: Absorption and Luminescence Spectra In: Gmelin Handbuch der Anerganische Chemie vol 20, Iransurane ,part D-1. (G KOCH, ed.) Springer Verlag. Berlin, 1975, pg 49.

9. CARNALL, W. T. and CROSSWHITE, H. M: Qptical Spectra and Electronic Structure of Actinide lons in Compounds and in Solution AN-84-90, dated Augus' 1985. 
10. NEWTON, T. W. and SULLIVAN, J. C. Actinide Carbonate Complexes in Aqueous Solution. In: Handbeak on the Physics and Chemistry of the Actinides (A. J. FREEMAN and C. KELLER, eds.) Elsevier, New York, 1985, pg 387.

11. BEITZ, J. V. and HESSLER, J. P: Oxidation state specific detection of transuranic ions in solution. Nuclear Tech 51, 169 (1981).

12. GUILLAIMMONT, R, CHEVALLIER, P., and ADLOFF, J. P: Identification of oxidation states of ultra-trace elements by radiation detection. Radiochim. Acta 40, 191 (1986).

13. HART, E J: Mechanism of the gamma-induced oxidation of formic acid in aqueous solution. J. Am. Chem. Soc. 73, 68 (1951).

14. CARNALL, W. T., BEITZ, J. V., and CROSSWHITE, H. Electronic energy level and intensity correlations in the spectra of the trivalent actinide aquo ions. III. $\mathrm{Bk}^{3+}$. J. Chem. Phys. 80, 2301-2308 (1984).

15. BEITZ, J. V., WESTER, D. W., and WILLIAMS, C. W: $5 f$ state interaction with inner coordination sphere ligands: $\mathrm{Es}^{3+}$ ion fluorescence in aqueous and organic phases. J. Less-Common Metals 93, 331 (1983).

16. HOBART,D. E, SAMHOUN, K., and PETERSON, J. R: Spectroelectrochemical studies of the actinides: stablization of americium (IV) in aqueous carbonate solution. Radiochim. Acta 31, 139 (1982).

17. CONWAY, J. G: Energy levels of Am IV in LaCl 3. J. Chem. Phys. 40. 2504 (1964).

18. NELSON, E T., and PATEL, C. K. N. Response of piezoelectric transducers used in pulsed optoacoustic spectroscopy. Optics Letters 6, 354 (1981).

19. KELL, G S: Precise representation of volume properties of water at one atmosphere. 4 Chem. Eng. Data 12, 66 (1967).

20. GREENSPAN, M. and TSCHIEGG, C. E. Speed of sound in water by a direct method. 」. Res. National Bureau of Standards 59, 249 (1957).

21. OSBORNE, M S., STIMSON, H. F., and GININGS, D. C: Measurements of heat capacity and heat of vaporization of water in the range 0 to $100 \mathrm{C}$. Bureau of Standards J. Research 23, 197 (1939).

22. BEITZ, J. V., JURSICH, G, and SULLIVAN, \&. C: Fluerescence studies of $\mathrm{Am}^{3+}$ in aqueous solution. In Rare Earths 1986 (H. B. SILBER, L. R. MORSS and L. E DELONG, eds.) Elsevier Sequoia, Lausanne, 1987, p. 301. 
23. YUSOV, A. B., PERMINOV, V. P., and KROT, N N: Photoluminescence of curium (III) beta-diketonates in solution. Soviet Radiochem. 28, 63 (1986).

24. CARNALL, W. T. and RAJNAK, K: Electronic energy level and intensity correlations in the spectra of the trivalent actinide aquo ions. $11 . \mathrm{Cm}^{3+}$. J. Chem. Phys. 63, 3510 (1975).

25. KIM, J. 1., BERMKPPF, M., LIERSE, CH., and KOPPOLD, F: Hydrolysis Reactions of Am(III) and Pu(VI) lons In Near-neutral Solutions. In: Geochemical Behavior of Disposed Radioactive Waste (G S. BARNEY, J. D. NAVFiATIL and W. W. SCHULZ, eds.) ACS Symposium Series vol 246, American Chemical Society, Washington, 1984, pg 115.

26. SILVA, $R$ J. The Behavior of Americium in Aqueous Carbonate Systems. In: Scientific Basis for Nuclear Waste Management VII (G L. MCVAY, ed) Materials Research Society Symposium Proceedings vol 26, North-Holland, New York, 1984, pg 875.

27. WESTER, D. W. and SULLIVAN, J. C: The absorption spectra of PUNI/, -PUVI,-Pu/iV/ produced electrochemically in carbonate-bicarbonate media Radixchem. Radioanal. Letters 57, 35 (1983). 


\section{Figure captions}

\section{Figure 1.}

Laser photoacoustic spectra of $2.5 \times 10^{-6} \mathrm{M}^{241} \mathrm{Am}^{3+}$ in $1.00 \mathrm{M} \mathrm{Na}_{2} \mathrm{CO}_{3}$ at $30 \mathrm{C}$. $60 \mathrm{C}$. and $90 \mathrm{C}$. The enhanced signal intensity with increasing temperature is attributed primarily to an increase in the photoacoustic response per unit absorbed laser energy. The spectra vere recorded using $3 \mathrm{~mJ}$ per laser pulse.

\section{Figure 2.}

Fluorescence excitation spectra of 325 ppt ${ }^{244} \mathrm{Cm}^{3+}$ in a simplified basalt groundwater $(0.01 \mathrm{M} \mathrm{NaCl}, \mathrm{pH}=7.5)$, shown as a solid line, and $1.63 \times 10^{-9} \mathrm{M}$ (398 ppt) ${ }^{244} \mathrm{Cm}^{3+}$ in $0.10 \mathrm{M} \mathrm{HClO}_{4}$, shown as a dashed line. The peaks correspond to the $F$ state[24] of $\mathrm{Cm}^{3+}$. The shift in peak position and increased bandwidth evident for $\mathrm{Cm}^{3+}$ in simplified basalt groundwater are attributed to formation of one or more $\mathrm{Cm}^{3+}$ hydroxo complexes. For comparison purposes, the spectra were scaled to have identical amplitudes. In both cases, $\mathrm{Cm}^{3+} \mathrm{A}$ state fluorescence was monitored.

\section{Figure 3.}

Fluorescence intensity versus time following pulsed laser excitation at 397.7 $\mathrm{nm}$ for 325 ppt ${ }^{244} \mathrm{Cm}^{3+}$ in simplified groundwater (upper solid line trace) and $1.63 \times 10^{-9} \mathrm{M}$ (398 ppt) ${ }^{244} \mathrm{Cm}^{3+}$ in $0.10 \mathrm{M} \mathrm{HClO}_{4}$ (lower solid line trace). Changes in fluorescence decay rates occur due to alteration of the inner coordination sphere of $\mathrm{Cm}^{3+}$ and are, therefore, indicative of formation of new $\mathrm{Cm}^{3+}$ species in simplified basalt groundwater. The dashed lines through sach solid line trace are the result of fitting the observed data te a single exponential decay model. For comparison purposes each data set was scaled to an initial intensity of 100 . In both cases, $\mathrm{Cm}^{3+}$ A state fluorescence was monitored. 


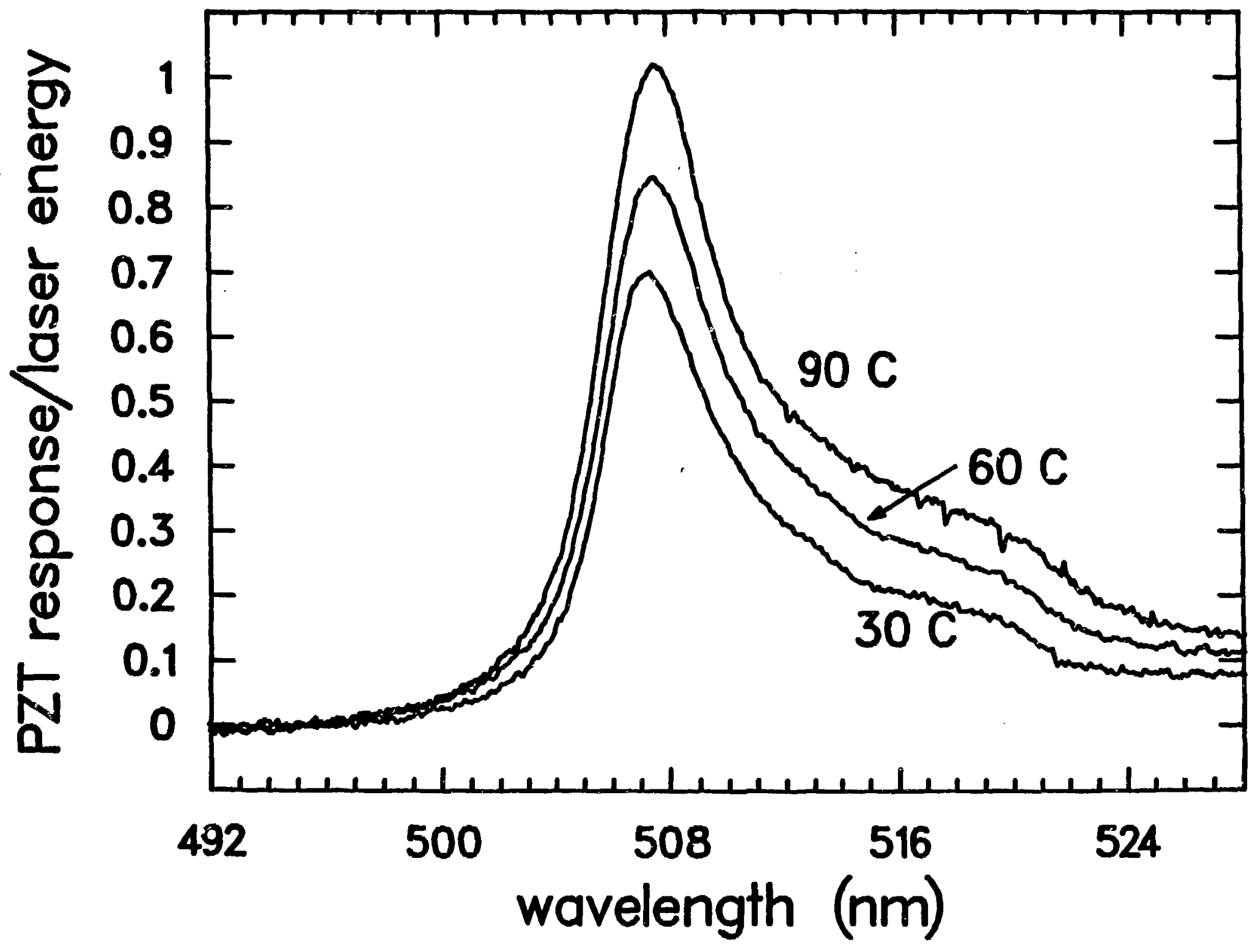


Figure 2

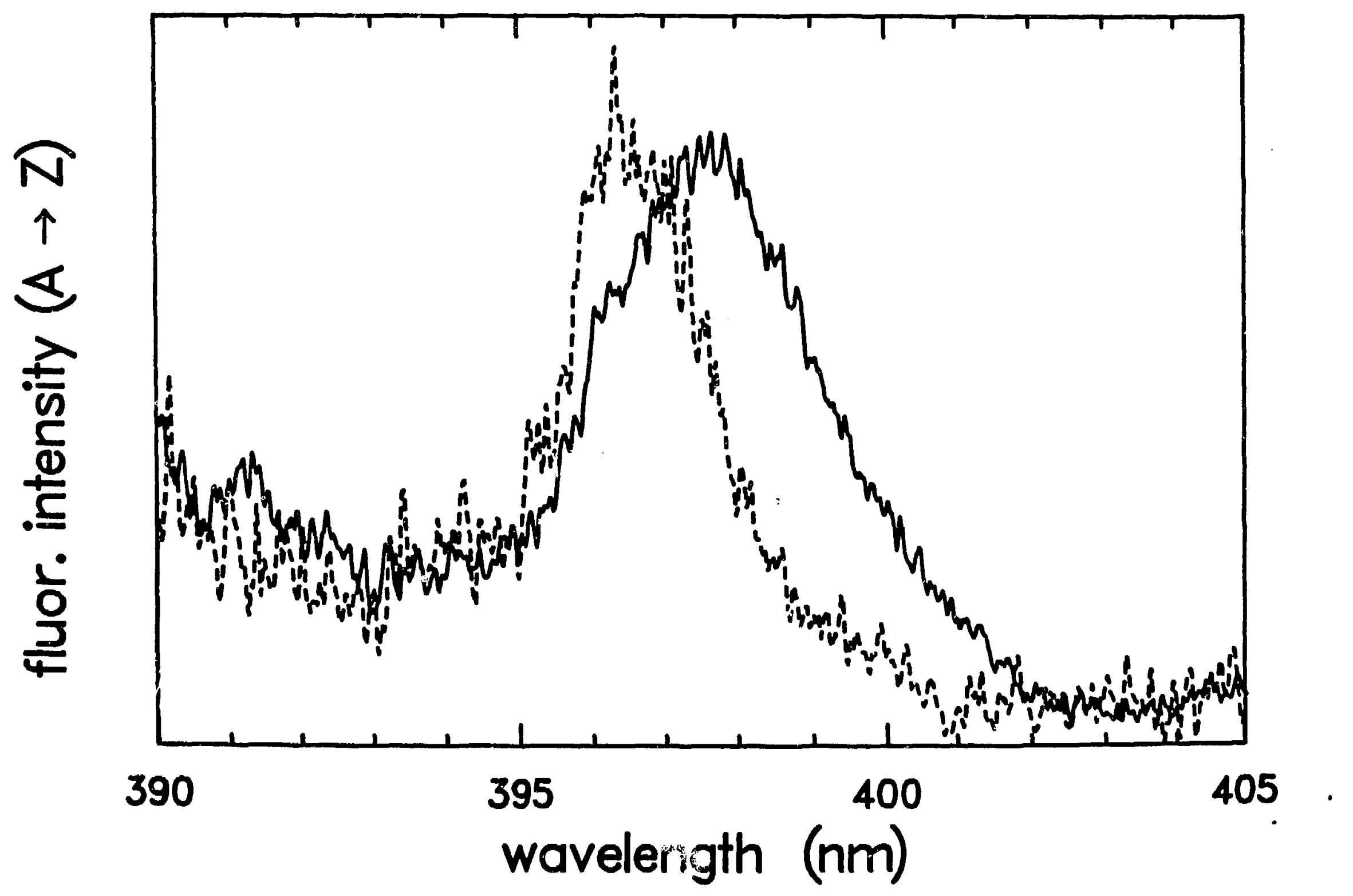


Figure 3

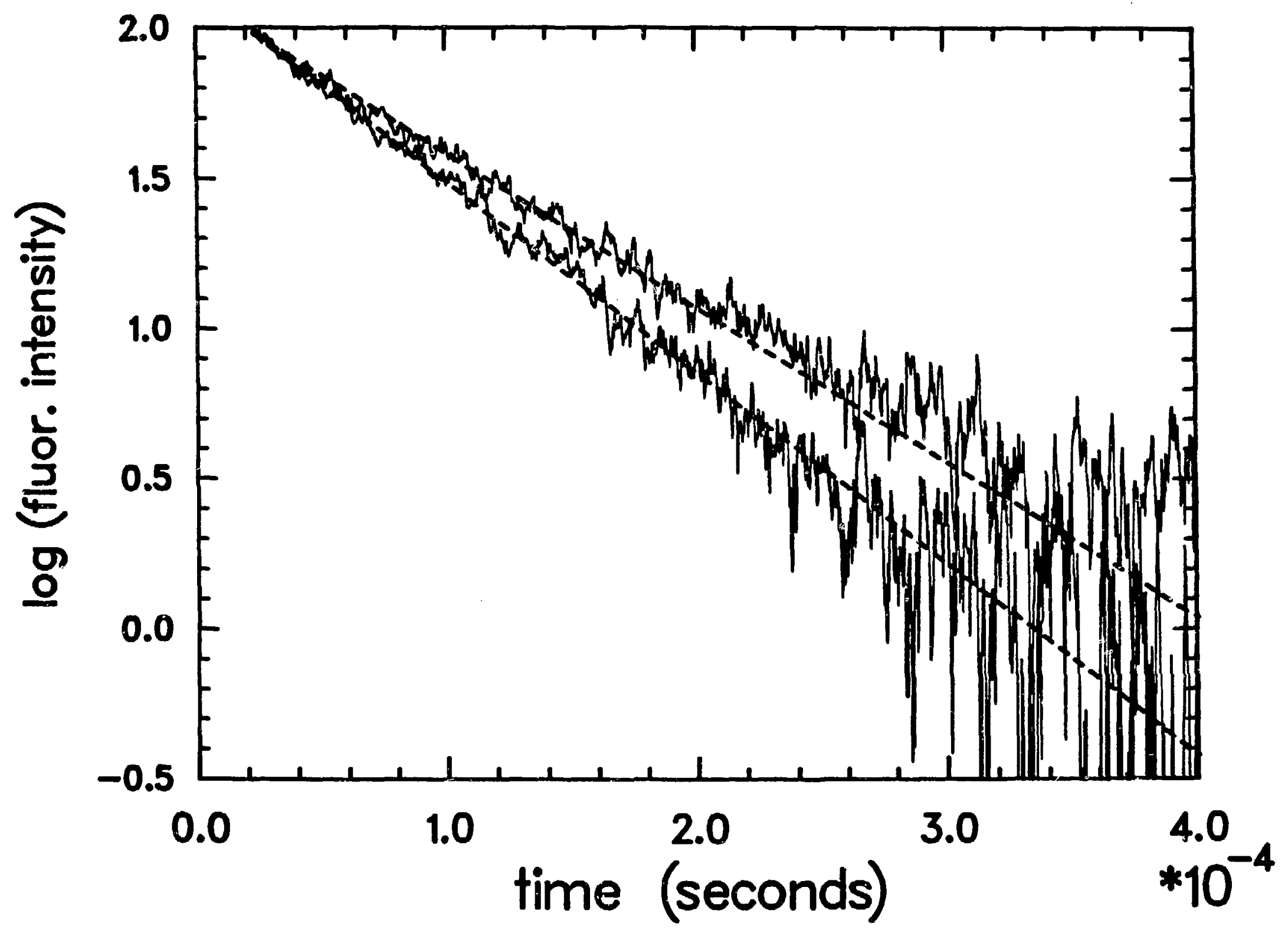

